\title{
Validation of Siemens T2* inline WIP package for quantification of cardiac and hepatic iron loading at $1.5 \mathrm{~T}$ and $3 \mathrm{~T}$
}

\author{
Mohammed H Alam ${ }^{1,2^{*}}$, Arun J Baksi ${ }^{1,2}$, Taigang He ${ }^{1}$, Gillian C Smith ${ }^{1,2}$, Cemil Izgi ${ }^{1}$, Ricardo Wage ${ }^{1}$, Peter Drivas ${ }^{1}$, \\ Andreas Greiser ${ }^{3}$, Bruce S Spottiswoode ${ }^{4}$, David Firmin ${ }^{1,2}$, Dudley J Pennell ${ }^{1,2}$
}

From 17th Annual SCMR Scientific Sessions

New Orleans, LA, USA. 16-19 January 2014

\section{Background}

The ability of $\mathrm{T} 2 *$ cardiovascular magnetic resonance (CMR) to identify cardiac iron loading has facilitated a dramatic reduction in mortality in patients with iron overload. There remains a worldwide need for improved access to iron evaluation. One route to achieving this would be simple in-line $\mathrm{T} 2 *$ analysis. We compared our validated T2* methods which use Royal Brompton Hospital (RBH) $\mathrm{T} 2$ * sequences with analysis by CMRtools against a novel work-in-progress (WIP) sequence and inline T2* analysis.

\section{Methods}

22 healthy volunteers and 78 patients were recruited (thalassaemia major 39 , sickle cell disease 15 , hereditary hemochromatosis 10 , other iron overload conditions 14) who were referred for routine iron assessment (53 male, aged 13 to 81 years). A $1.5 \mathrm{~T}$ study (MAGNETOM Avanto, Siemens AG Healthcare Sector, Erlangen, Germany) was performed on all subjects, from whom a subset of 50 underwent an additional 3T study (MAGNETOM Skyra). The same mid-ventricular short axis cardiac slice and transaxial slice through the liver were used to acquire both RBH T2* images and WIP T2* maps for each scan. Cardiac white blood (WB) and black blood (BB) sequences were acquired. All data acquisition and ROI based analysis was performed by a single observer.

\section{Results}

At $1.5 \mathrm{~T}$, liver $\mathrm{T} 2 *$ values ranged from $0.8-33 \mathrm{~ms}$ (median $5.1 \mathrm{~ms}$ ) and cardiac T2* values from $6.6-49 \mathrm{~ms}$ (median $31 \mathrm{~ms}$ ). There was good agreement between RBH-CMRtools T2* and Siemens T2* WIP maps with results close to the line of identity and linear regression close to 1 (Figure 1); $\mathrm{R}^{2}$ values for $\mathrm{WB}, \mathrm{BB}$ and liver $\mathrm{T} 2$ * were $0.969,0.945$ and 0.995 respectively at $1.5 \mathrm{~T}$ and $0.963,0.982$ and 0.993 respectively at $3 \mathrm{~T}$. The coefficient of variation was $5.5-7.6 \%$ across techniques at $1.5 \mathrm{~T}$ and $5.5-7.9 \%$ at $3 \mathrm{~T}$. Accurate delineation of the septum was difficult on some T2* WIP maps due to artefacts. The inability to manually correct for noise by truncation of erroneous later echo times lead to some overestimation of $\mathrm{T}_{2}$ * using the WIP technique compared to RBHCMRtools.

\section{Conclusions}

The Siemens WIP T2* mapping sequence and analysis performed well against the standard RBH-CMRtools T2* package at both $1.5 \mathrm{~T}$ and $3 \mathrm{~T}$. Inline $\mathrm{T} 2 *$ mapping in 


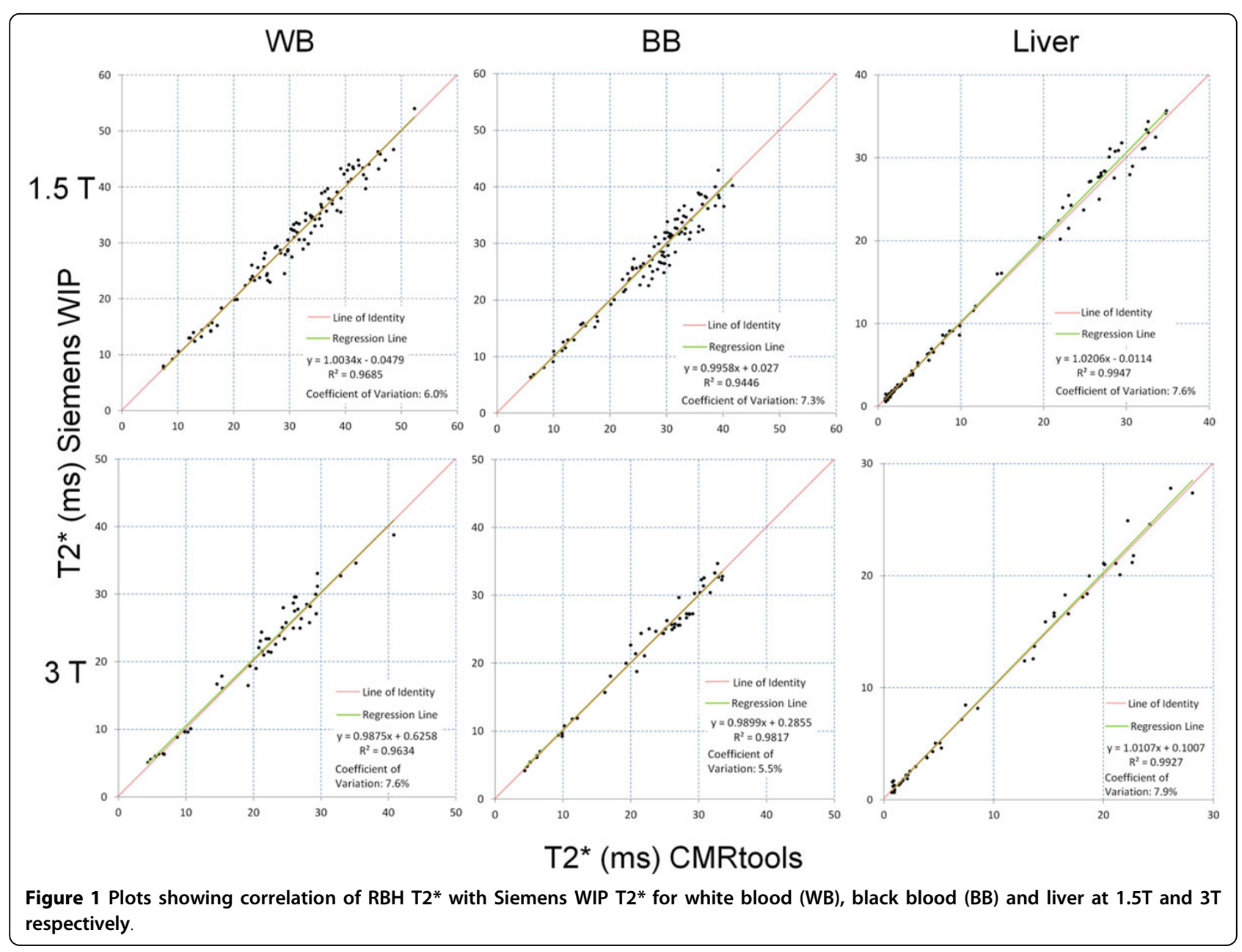

combination with a simple ROI analysis has the potential to improve global access to iron assessment.

\section{Funding}

This research was supported by the NIHR Cardiovascular Biomedical Research Unit at Royal Brompton \& Harefield NHS Foundation Trust and Imperial College London.

\section{Authors' details}

${ }^{1} \mathrm{NIHR}$ Cardiovascular Biomedical Research Unit, Royal Brompton Hospital, London, UK. ${ }^{2}$ Imperial College London, London, UK. ${ }^{3}$ Siemens AG Healthcare Sector, Erlangen, Germany. ${ }^{4}$ Siemens Healthcare USA Inc., Malvern,

Pennsylvania, USA.

Published: 16 January 2014

\section{Submit your next manuscript to BioMed Central} and take full advantage of:

- Convenient online submission

- Thorough peer review

- No space constraints or color figure charges

- Immediate publication on acceptance

- Inclusion in PubMed, CAS, Scopus and Google Scholar

- Research which is freely available for redistribution 